\title{
The Generic Structure of Print Advertisement of Elizabeth Arden's INTERVENE: A Multimodal Discourse Analysis
}

\author{
Aylanda Dwi Nugroho \\ English Department, Faculty of Letters, Petra Christian University, Siwalankerto 121-131, \\ Surabaya 60236, East Java, Indonesia \\ e-mail: g0700751@nus.edu.sg; aylanda@peter.petra.ac.id
}

\begin{abstract}
The Elizabeth Arden campaign with Catherine Zeta-Jones as the brand ambassador has deployed the semiotic resources of language and visual images. The analysis of this paper is based on the systemic functional linguistics (SFL) proposed by Halliday $(1985,1994)$ and Halliday and Matthiessen (2004), which says that a text is understood to simultaneously function three metafunctions: Ideational, Interpersonal and Textual. O’Toole's (1994) framework of analysing visual images, which follows the main concept of SFL, is also used in the analysis. A multimodal discourse analysis is then applied to analyse one of the series, Intervene, using Cheong's framework (2004), which combined both frameworks to find the generic structure of this advertisement. Further, this paper also analyses the intersemiosis of the linguistic and the visual resources using Wee's (2009) intersemiotic mechanisms. It concludes that the interplay of the language and the visual image has proved to be very effective in the meaning-making process of this print advertisement.
\end{abstract}

Key words: Multimodal Discourse Analysis, semiotic resources, linguistic resource, visual resource, print advertisement

Today's texts have developed very rapidly in using a great variety of modes, channels and media from print to electronic and web-based media. The modern technology has also equipped media in creating, transferring and editing pictures which can consist of minimally two semiotic resources. These new media consist of not only language or linguistic text but also visual images such as pictures, photos, cartoons, maps and many others. They have a range of still images in print, electronic and web-based media to even moving images in web-based media. This makes an analysis of the linguistic text only while ignoring the visual images and the interplay of the two insufficient. 
Multimodality or multimodal discourse analysis provides the tools and techniques to analyse texts which employ more than one mode of discourse. It is interesting to see how different semiotic resources are deployed simultaneously in the process of making the intended meaning well-projected by the advertisement designers to the viewers, the potential buyers of the advertised product.

Halliday (1985, 1994), and Halliday and Matthiessen (2004) constructed Systemic Functional Grammar that made it possible to say sensible and useful things about any text, spoken or written, in modern English. The underlying theory is a systemic theory, which argues that meaning is a choice, and by which a language, or any other semiotic system, "is interpreted as networks of interlocking options: 'either this, or that, or the other', 'either more like the one or more like the other', and so on" (p. xiv). Furthermore, it is named functional because of three distinct characteristics:

1. "It is designed to account for how the language is used

2. The fundamental components of meaning in language are functional components, that is, the metafunctions of ideational, interpersonal and textual meanings

3. Each element in a language is explained by reference to its function in the total linguistic system" (p. xiii).

The Ideational metafunction shows the ideational meaning, that is, the meaning of the language which encodes the experience of the speaker or writer. The Interpersonal metafunction makes interpersonal meaning in which language encodes the interaction between the speaker and the writer. The Textual metafunction indicates the uses of language to organize the experiential, logical and interpersonal meanings into a coherent expression. All these three metafunctions work simultaneously in every expression of the language.

Halliday (1985) divides the levels of language into Extralinguistic levels and Linguistic levels. The Extralinguistic levels include the Context of Culture, which shapes the meanings of any interaction in social practices, and the Context of Situation, which gives substance to the words and grammatical patterns produced by speakers or writers. These two contexts are realised in the Linguistic levels, which are divided into two levels: the Content level and the Expression level. The Content level is further divided into Semantics and Lexicogrammar. These are further 
realised in the Expression level, which include the Phonology (in speaking), Gestures (in signed languages) and Graphology (in writing). Figure 1 visualises this language levels.

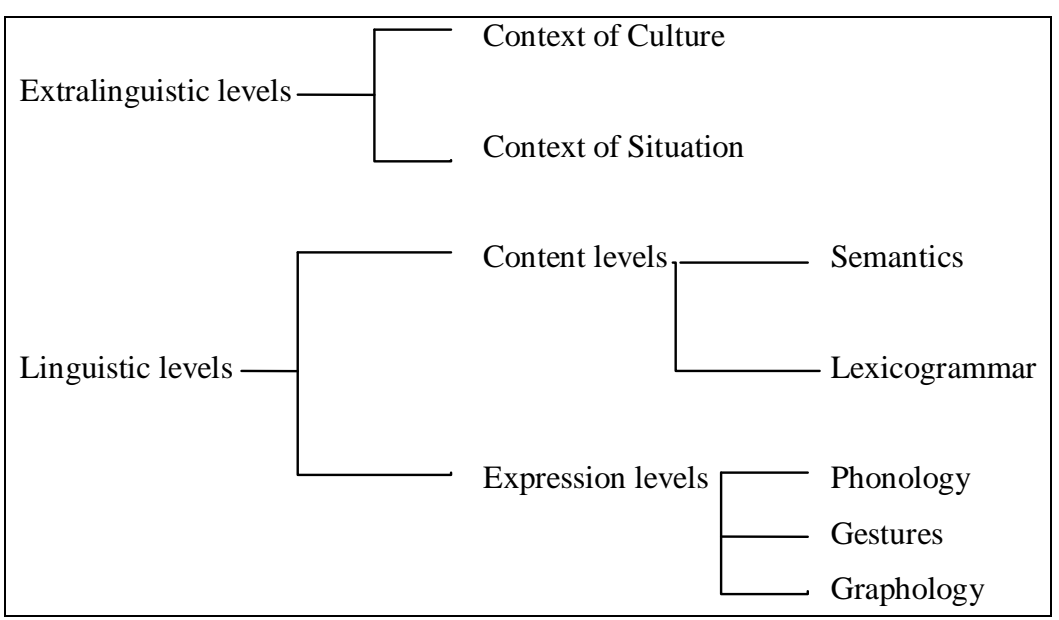

Figure 1. Levels of Language (summarized from Halliday, 1985)

Halliday's linguistic framework has been adopted by many other scholars in analysing other discourse modes. Kress and van Leeuwen (1996) modified the functional linguistic analysis for analyzing visual images. Van Leeuwen (1999) applied such framework in analyzing music. Martinec (1998) also adopted it to analyze actions. O’Toole (1994) adapted Halliday's framework to analyze paintings, sculpture and architecture. Since then all of these frameworks have been applied in Multimodal Discourse Analysis to analyze the intersemiosis of the verbal, visual, symbolic and other semiotic resources in the meaning-making processes. In relation to Critical Discourse Analysis (CDA), Fairclough (1995) shows the relevance of analysing texts and talks from a multimodal perspective because texts and talks currently use more than one semiotic resource. He states that

... written (printed) texts are also increasingly becoming multisemiotic texts, not only because they incorporate photographs and diagrams, but also because the graphic design of the page is becoming an ever more salient factor in evaluation of written texts (p. 4). 
It is also argued that often it is the interplay of the verbal, the visual and/or other resources that is more important in the meaning-making process than the linguistic resource or the visual resource alone.

The second framework is that of analyzing picture which was proposed by O’Toole (1994) and was adapted from the systemic functional linguistics. He named the three functions as Representational, Modal and Compositional to Halliday's Ideational, Interpersonal and Textual respectively. He also modified Halliday's levels of language into levels of visual images consisting of Work, Episode, Figure and Member. His framework is summarised in Table 1.

Table 1. Framework of Analyzing Paintings (O’Toole, 1994, p. 24)

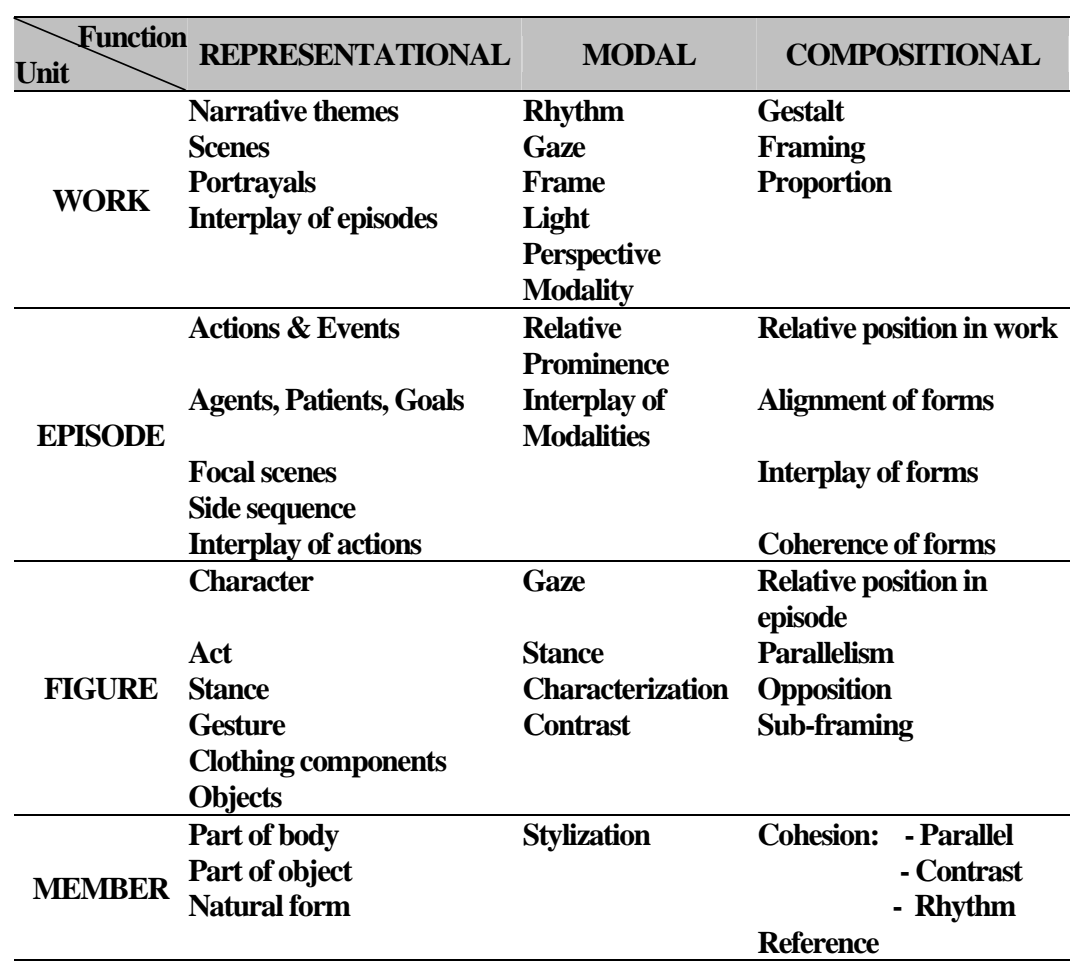

Cheong (2004) further combined both frameworks to analyze print advertisements. She proposed a generic structure of print advertisement, that is, the elements that occurred in print advertisements in general. The ad 
is divided into two components: the Visual Images and the Linguistic. This component set consists of the Lead, the Display and the Emblem. The Lead is or should be the most salient image because it is or should be the main focus of attention that attracts the viewers or the one that the viewers give to the advertisement. It is constructed by smaller elements categorised as the Locus of Attention (LoA), which is the most salient item or items in the Lead; and the Complementary Locus of Attention (Comp.LoA), that is, the background or other visuals which are less salient than the LoA but complementing LoA. The second element, the Display, shows the characteristics of the Lead in a two by two matrix of Explicit - Implicit and Congruent - Incongruent. A Lead is said to be Explicit if the picture is about a tangible object and Implicit if the intangible product or service is given tangible form through another medium. In addition, the Lead is called Congruent if the product is not realized through symbolism and Incongruent if the product is realized through symbolism. The third element in the visual image component is the Emblem, which is usually the company's logo.

The second component, the Linguistic one, is formed of several elements such as Emblem, Announcement, Enhancer, Tag, and Call-andVisit Information. Emblem in the linguistic component comprises the linguistic slogan which may accompany the visual Emblem, the company's logo. Announcement is the most salient linguistic text in the advertisement; and based on the level of salience, Announcement consists of the Primary Announcement and Secondary Announcement, which are deployed to capture the readers' attention of the advertised product. Next, Enhancer is the part of the advertisement which explains further the Announcement, and it is usually in smaller fonts and in the form of a paragraph. Tag is the additional phrase or clause to further comment the visual and usually brief. Finally, because the print advertisement is a promotional medium, Call-and-Visit Information is necessary to be included in the advertisement for the readers to contact the company if they are interested in the products and services.

In her research on four print advertisements in Singapore, Cheong found that the generic structure of print advertisement is

Lead $^{\wedge}(\text { Display })^{\wedge}$ Emblem $^{\wedge}(\text { Announcement })^{\wedge}(\text { Enhancer })^{\wedge}(\text { Tag })^{\wedge}(C$ all-and-Visit Information) 
They symbol "^" means "followed by", and the brackets mean that the element inside them is optional. She concluded that the obligatory elements that always occur in print advertisement are the Lead and the Emblem, while the others are optional.

Besides analysing each semiotic resource deployed in this advertisement , this paper also analyses the intersemiosis of both resources. According to Wee (2009), the meaning-making process may often achieved from the collaboration of both resources. Wee further suggests that the semantic collaboration between the linguistic and the visual resources include three possible processes: Complement, Supplement and Displacement. Further, she proposes that the intersemiotic mechanisms which facilitate the intersemiosis between different semiotic resources are below:

1. Intersemiotic Juxtaposition: the semiotic resources are spatially organized to facilitate intersemiotic process

2. Intersemiotic Parallelism: one semiotic resource corresponds with the other resource(s)

3. Intersemiotic Prominence: one semiotic resource is incorporated to draw attention to the other resource(s)

4. Intersemiotic Contrast: one semiotic resource is contrasted to the other resource(s)

5. Intersemiotic Negotiation: The semiotic resource is macro-shifted in meanings and involves re-contextualization to explicate meanings.

\section{METHODS}

The data of this study was the Elizabeth Arden print advertisement for the moisturizing cream Intervene (www.elizabetharden.com) in the series of Catherine Zeta-Jones as the brand ambassador (reprinted with kind permission from Elizabeth Arden). Among the other print advertisements of Catherine Zeta-Jones campaign series, this advertisement of Intervene was chosen because the model was photographed not only on the face but also the body. This widens the interpretation of an advertisement of a moisturizing cream, which most users apply on their face (and neck) only. The original coloured ad depicted the dress of the model, the product and the background in a monochromatic purplish grey like the colour of the product container (The printed advertisement can be seen in black and white in this article). 
The advertisement was first analysed on its visual resource by applying O’Toole's (1994) framework and Cheong's (2004) generic structure on the visual elements. Next, the linguistic resource was analysed in terms of SFL and Cheong's generic structure on the linguistic elements. Finally, Wee's (2009) intersemiotic mechanisms were considered in analysing the interplay of the two resources.

\section{FINDINGS AND DISCUSSION}

\section{The Visual Component}

The Lead, that is the most salient visual image of this ad, is definitely the model, Catherine Zeta-Jones. More precisely, following Cheong's framework (2004), the Locus of Attention (LoA) is her face, because she is gazing directly towards the camera and thus seems to look at directly to the viewers. By doing so, she is thus fully captivating and engaging the viewers' attention to look back at her. O’Toole (1994) suggested that Gaze is the most important element in the Modal function because the presence or the absence of gaze can or cannot build the interpersonal relation between the viewer and the object in the image. In this advertisement the bright, wide and happy smile of the model is showing two rows of white and healthy teeth. Her eyes are also 'smiling' happily. What is most important is the fair, healthy and fresh complexion, indicating 'young' and healthy skin. Although the LoA is her face, it does not mean that the other parts of her body are not important in creating such impression. Her hair is flowing freely blown by soft winds as the result of moving. Her posture is straight. Her low-neck evening gown is confidently revealing her white, fresh neck and chest. Her arms suggest she is in the middle of moving.

At the time of being appointed the Brand Ambassador of Elizabeth Arden, Catherine Zeta-Jones was not a young artist or celebrity anymore. She was married; she was in her mid 30s and had obtained a number of prestigious film awards including BAFTA, Golden Globe, Screen Actors Guild Awards and the Academy Awards. She projected an image of a mature, strong-hearted, and talented woman; a perfect image that Elizabeth Arden needed at that time to refresh their classic image into a modern outgoing woman for the $21^{\text {st }}$ century (www.elizabetharden.com) 


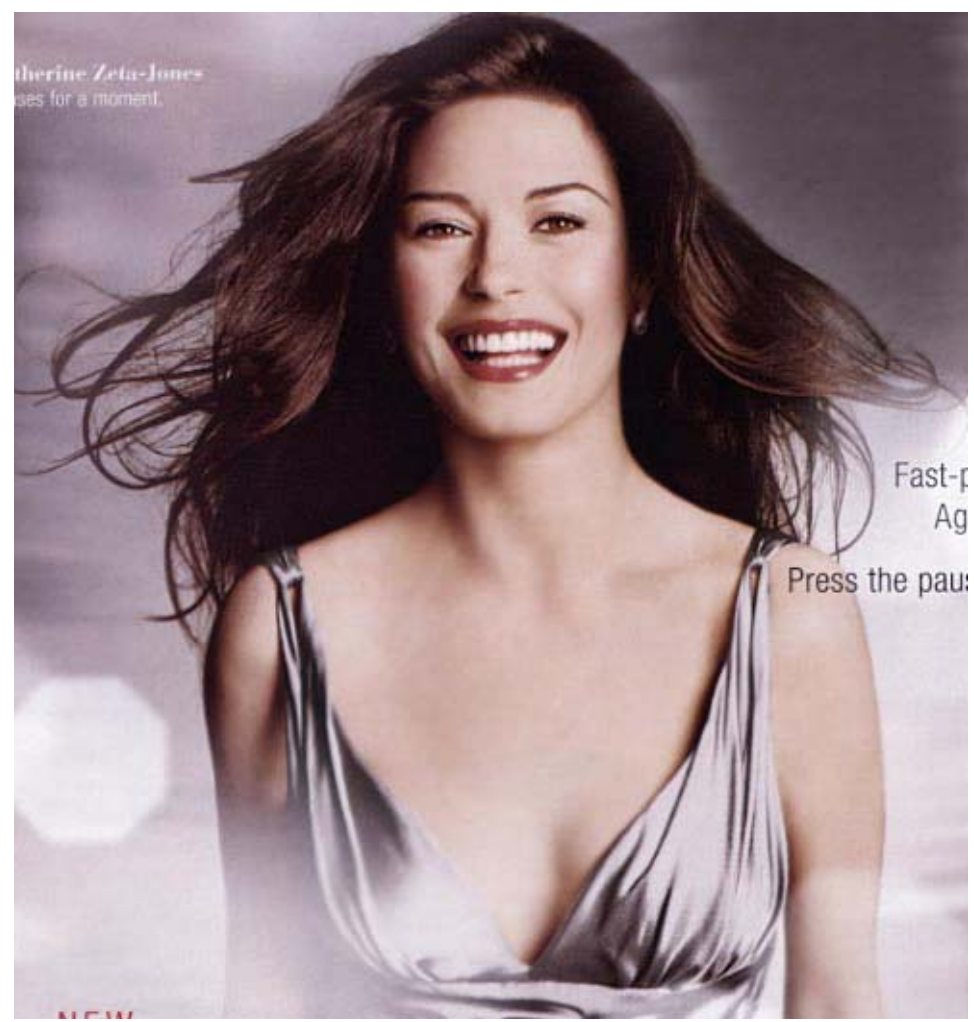

Figure 2. The Lead: Locus of Attention

(www.elizabetharden.com)

The other visual image is the picture of products itself at the bottom right corner. Together with the background, it composes the Complement of Locus of Attention (Comp.LoA). Both of them supplement the LoA, the face of the model, to produce a relation commonly suggesting that young and fresh look is the result of that moisturizing cream. The background looks like disco lights in a club (seen here as lighter small circles). Both the LoA and the Comp.LoA project an image of a mature (not-so-young) confident woman who is active, at her peak time of her life, having a good time in a club, and enjoying the night life. This implies that she is popular and in the company of close friends (See the whole print in Plate 1. Data Analysis). Kress and van Leeuwen (1996) emphasize how colour is very 
important in creating meaning. This advertisement uses monochromatic purplish grey in accordance with the colour of the product's bottle. This colour suggests a charming, mature and royal sense.

Finally, the last element of the Visual resource is the Emblem. The famous Elizabeth Arden red door is put at the bottom left corner of the ads.

\section{The Linguistic Component}

Following Cheong's Framework, the most salient linguistic component is Primary Announcement. In this ad, it is the phrases in the big font, including the surrounding words or phrases that form a unit. The name 'Intervene' is printed in big font, dark grey and all capital letters, supplemented by 'New' in a prominent red and in all capital letters. Below 'Intervene', 'Pause \& Effect' is put there still in all capitals but in smaller font and softer colour; and finally, 'Moisture Cream and Lotion SPF 15' is printed in even smaller font, soft colour and capital-lower letters.

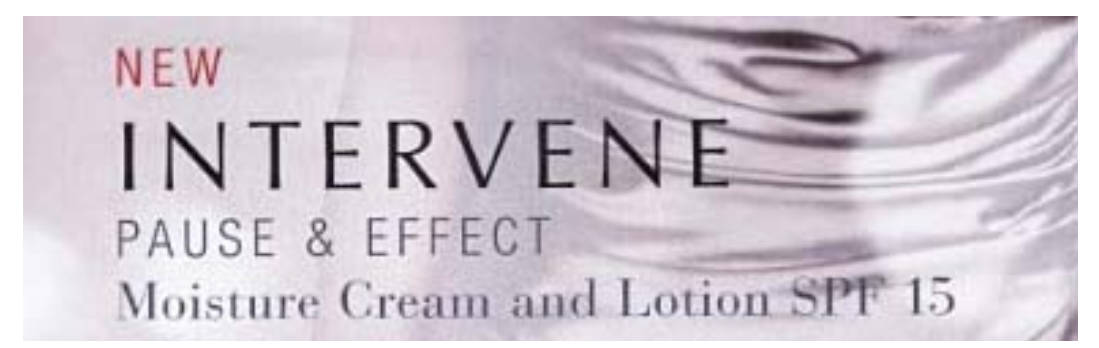

Figure 3. The Primary Announcement

Reading these lines may not give viewers a direct comprehension about this ad. While viewers know that the product is new and named 'Intervene' and that it is a moisture cream and lotion with SPF 15, viewers may question the relevance of "Pause \& Effect" in this part.

This temporary confusion is clarified by the Secondary Announcement in Figure 4. It consists of two phrases ("Fast-paced life" and "Aging signs") and one imperative sentence ("Press the pause button"). The "Pause" in the Primary Announcement is connected to the "pause button" in the Secondary Announcement. Yet, the meaning is not clear. The Enhancer below the Primary Announcement further clarifies what the advertisement wants to say. 


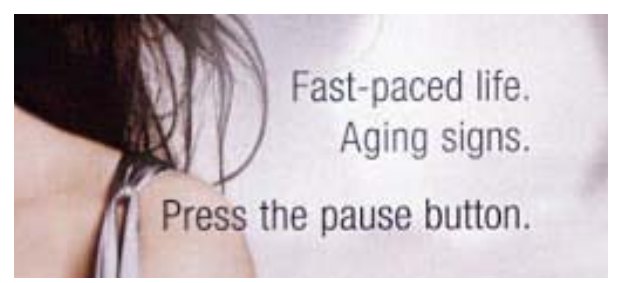

\section{Figure 4. Secondary Announcement}

Next, the "Fast-paced life" and "Aging skin" in the Secondary Announcement are connected with the same phrase or word in the Enhancer.

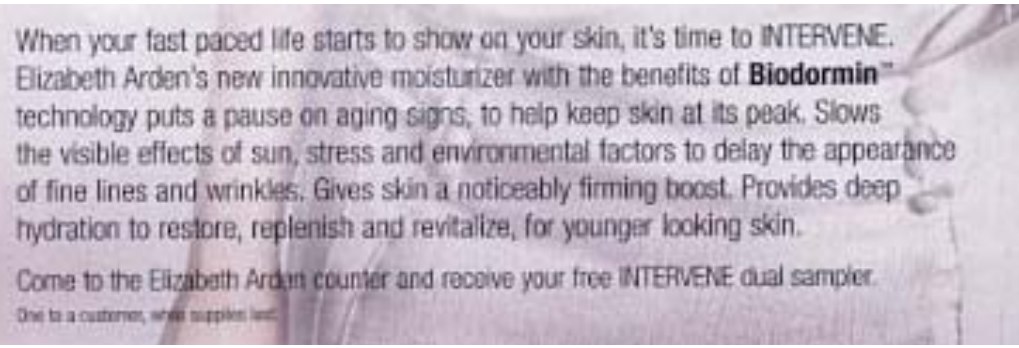

\section{Figure 5. The Enhancer}

The name's product, Intervene, meaning "to come between (others) in time” (Oxford Advance Learner's Dictionary of Current English), is used as a verbal, in the first sentence:

"When your fast paced life starts to show on your skin, it's time to INTERVENE."

The second sentence provides an authority sense by mentioning the chemical substance and the innovative technology that can help women have younger looking skin. The next three 'sentences' show the benefits of the cream. Although they do not have subject, they are not imperative sentences either because the verb is for the third singular subjects (verb + $s$ ). The subject is presumably this moisture cream being advertised.

The Enhancer is closed with an invitation to come to the counter and get a free sampler. Interestingly, right under the invitation, a disclaimer is 
put in a very small font, and it is written, "One to a customer, while supplies last."

The other linguistic elements are small items such as some Tags, Calland-Visit Information, and the Emblem.

Table 2. Smaller items of the advertisement

\begin{tabular}{|c|c|c|}
\hline Items & Element & Location \\
\hline $\begin{array}{l}\text { Canlueriue letin-Jones } \\
\text { pauses tor a monent }\end{array}$ & Tag & Top let corner \\
\hline 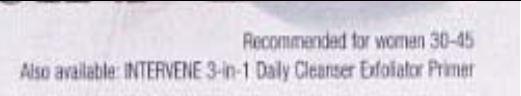 & Tag & $\begin{array}{l}\text { Below the picture of } \\
\text { the product }\end{array}$ \\
\hline Macy's & Tag & Top right corner \\
\hline elizabetharden.com & Call-and-Visit & Below the Emblem \\
\hline Elizabeth Arden & $\begin{array}{l}\text { Emblem } \\
\text { (Ling) }+ \text { (Visual }\end{array}$ & Bottom \\
\hline
\end{tabular}

However, the separate analysis on the visual resource and the linguistic resource has not shown the whole meaning of the advertisement. The visual alone just shows a charming, looking-young, happy, healthy, active, confident woman, and the picture of the cream product. The linguistic resource, on the other hand, tells about the life, the skin, the cream and its benefit, and invites the viewers to come to the shop counters. Therefore, this advertisement is further analyzed by looking into the interplay between the visual and the linguistic resources.

\section{The Interplay between Visual and Linguistic Components}

Using Cheong's framework of analysis above, it can be seen that there are a number of interplays among the elements, which are strongly used to send the message across to the readers. The first interplay is within the visual component between LoA and Comp.LoA. Dressing in purplish grey satin gown which is monochromatic with the product (darker purplish grey) and background (lighter purplish grey), the LoA is smiling wide with her freestyle hair softly blown by the wind as if she is in the middle of 
moving. She also looks young, radiant and happy. Using O’Toole's term, the colours of the elements of this advertisement are rhyming to one another. The Modal, Representational and Compositional functions work together in this advertisement to suggest the happy, young, healthy, confident, ready-to-face-the-world personality of LoA. It can be seen from her direct gaze to the viewers and her body which openly confronts the viewers in a levelling perspective to suggest a confident character and equal relation with the viewers. In addition, the vertical stance of LoA and the overlapping tall bottle of the product create a vertical 'Gestalt' suggesting the impression of a tall, positive, and stable person and thus experiencing a healthy life. Modally, LoA receives the full light, especially the face, the most salient element of the LoA. The Comp.LoA, the background, indicates out-of-focus lights from a far to suggest night life.

The second interplay can be seen in the linguistic text, between the Primary Announcement (PA) and Secondary Announcement (SA). The word "Pause" in PA is complemented with the "Press the pause button" in SA. Without reading the "pause" in SA, the readers may not be able to understand the intention of using the word "pause" in "PAUSE \& EFFECT" in PA. Beside this, the phrases "Fast-paced life." and "Aging signs." in SA also further clarify what we need to pause ourselves from. When our life is busy (fast-pacing), we do not have time to take care of our skin because it usually takes a long time to indulge ourselves in a beauty salon. So, it is suggested that the viewers or readers (the female readers, most probably, who are in their mid careers and lead a busy life) pause for a while for two things: from their busy life and those aging signs. Without connecting the Primary to the Secondary Announcements, the readers may find difficulties in understanding those word and phrases.

Following Wee's framework of integrating the visual images and the text (2004), it is much more interesting to see the inter-semiotic mechanism of Loa and SA. The idea of "pause" is strengthened when we see how LoA complements SA in a way that LoA looks as if she is in the middle of walking and then is being paused or freezed. This can be seen from her hair which is softly blown by the wind; her right arm which is a bit behind her right side and her left arm a bit in front of her left side. Metaphorically, it is used to give a suggestion as if we can pause ourselves from our life as we can pause a DVD movie. This analogy is used attractively, because the LoA and the beaming lights in the background indicate that something is in the middle of happening and then it is being paused. 


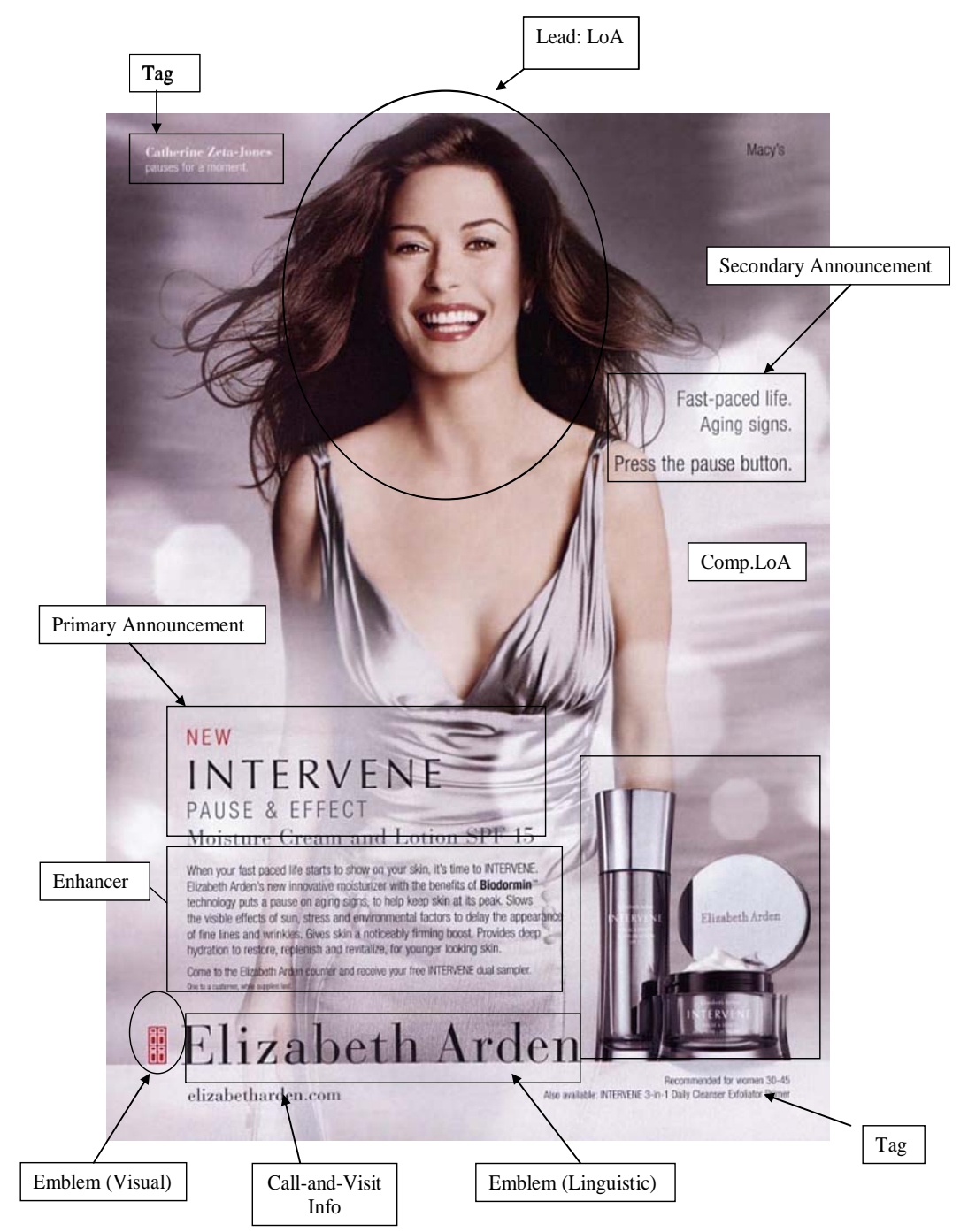

Plate 1. Data Analysis

The other ideas, "fast-paced life" and "aging signs", are also projected through the multiple interplays among the image of LoA, the Secondary Announcement, the Enhancer and one of the Tags. There is an assumed fact that celebrities' life is very busy ( $\rightarrow$ "fast-paced life") and the star, 
Catherine Zeta-Jones, is famous, and thus busy, but not that young anymore ( $\rightarrow$ "aging signs"). However, she can still look healthy, happy, fresh, active, confident and young in this advertisement because she "pauses" her life for a moment (the top left corner of Tag) and allow INTERVENE (the moisture cream) to intervene her life and does the magic with all the benefits that it has (stated in Enhancer).

Looking at the Composition of the items in this advertisement, the image of the product overlaps with the left arm of the LoA. The Enhancer also overlaps with the middle part of LoA's body, and the lighted LoA's as the result of the beaming lights from the background functions very well to show the Enhancer. Thus, it can be concluded that

the intersemiotic process of this advertisement is Complement, and in integrating the visual images and the linguistics text to create meaning, this advertisement has made use of Intersemiotic Juxtaposition, Prominence and Parallelism mechanisms (Wee, 2009).

One preferred reading of this advertisement can then be suggested the following: first, the LoA especially the face; second, the Primary Announcement; third, the Secondary Announcement; then the Enhancer; next, the Catherine Zeta-Jones Tag; and then followed by the product image, the logo the "Recommended" Tag and/or the website. From this reading path, the advertisement can be understood to project the image of younger, healthy and happy look of not-so-young professionals when they use the moisture cream with its proven technology benefits as it has been proven through the product icon.

\section{CONCLUSION}

In summary, this advertisement has been well pre-thought and composed in such a way that it suggests a compact and solid idea of keeping looking younger for not-so-young females who now hold many major positions in their professions. This advertisement is realistic in a way that these potential viewers do not need to look too young, which is not possible. They just need to look a bit younger by taking a short pause and using the cream, and soon they can continue to their exciting lifestyle. Every visual and linguistic item in the ad is arranged very well so they complement and support one another to project the positive image to attract the viewers to buy the product. 


\section{REFERENCES}

Cheong, Y. Y. (2004). The construal of ideational meaning in print advertisements. In K. L. O’Halloran (Ed.), Multimodal discourse analysis: Systemicfunctional perspectives (pp. 163-195). London and New York: Continuum.

Fairclough, N. (1995). Critical discourse analysis: The critical study of language. London and New York. Longman.

Halliday, M. A. K. (1985). An introduction to functional grammar. London: Arnold.

(1994). An introduction to functional grammar ( $2^{\text {nd }}$ edition). London: Arnold.

Halliday, M. A. K., \& Matthiessen, C. M. I. M. (2004). An introduction to functional grammar ( $\left.3^{\text {rd }} \mathrm{ed}\right)$. London: Arnold.

Hornby, A. S. (1980). Oxford advance learner's dictionary of current English. Oxford: Oxford University Press.

Kress, G., \& van Leeuwen, T. (1996). Reading images: The grammar of visual design. London: Routledge.

Martinec, R. (1998). Cohesion in action. Semiotica, 120(1), 161-180.

O’Toole, M. (1994). The language of displayed art. London: Leicester University Press.

Van Leeuwen, T. (1999). Speech, music, sound. London: Macmillan.

Wee, S H N C. (2009). Newspaper reporting of SARS in Singapore: A systemic functional approach. Unpublished doctoral dissertation, National University of Singapore, Singapore. 